\title{
Herpes Zoster Vaccination Reduces Risk of Dementia
}

\author{
STEVEN LEHRER ${ }^{1}$ and PETER H. RHEINSTEIN ${ }^{2}$ \\ ${ }^{1}$ Department of Radiation Oncology, Icahn School of Medicine at Mount Sinai, New York, NY, U.S.A.; \\ ${ }^{2}$ Severn Health Solutions, Severna Park, MD, U.S.A.
}

\begin{abstract}
Background/Aim: The relationship of herpes viruses and herpes zoster (HZ) with dementia and Alzheimer's disease is controversial. This study evaluated the relationship between $H Z$ vaccination and cognitive impairment. Patients and Methods: We used data from The Behavioral Risk Factor Surveillance System (BRFSS) to evaluate the relationship between $H Z$ vaccination and cognitive impairment. Results: Using BRFSS 2017 data, we assessed HZ vaccination status in 275 subjects whose social activities were hampered by disorientation or memory loss. $61.6 \%$ of vaccinated subjects $(n=61)$ and $46.6 \%$ of unvaccinated subjects $(n=82)$ never had social activities hampered by disorientation or memory loss. The result is significant ( $p=0.025$, two- sided Fisher exact test). The results of multivariate linear regression analysis, considering social activities hampered by disorientation or memory loss as a dependent variable, and vaccination (yes or no), sex, and education level as independent variables, showed that the effect of vaccination--reducing risk of social activities hampered by disorientation or memory loss--was significant $(p=0.03)$. Conclusion: Our finding that $H Z$ vaccination reduces the risk of dementia is consistent with the link between viruses and $A D$. Herpes viruses-induced reactivation of embryologic pathways silenced at birth could be one of the pathologic processes in Alzheimer's disease.
\end{abstract}

The relationship of herpes zoster (HZ) with dementia and Alzheimer's disease (AD) is controversial. HZ has been linked to a slightly higher risk of dementia, while antiviral medication has been linked to a lower chance of developing dementia after

This article is freely accessible online.

Correspondence to: Dr. Steven Lehrer, Box 1236 Radiation Oncology, Mount Sinai Medical Center, 1 Gustave L. Levy Place, New York 10029, U.S.A. Tel: +1 2127657132, e-mail: steven.lehrer@mssm.edu

Key Words: Shingles, herpes zoster, vaccination, dementia.
$\mathrm{HZ}$ diagnosis (1). Bae et al. investigated the link between $\mathrm{HZ}$ and dementia, as well as the impact of antiviral medication on dementia risk. HZ was linked to a higher risk of dementia, whereas antiviral therapy was linked to a lower risk of dementia in $\mathrm{HZ}$ patients (2). Tsai et al. discovered an elevated risk of dementia in patients infected with herpes zoster ophthalmicus (3). Other research (4) has supported these findings. However, in a case-control study, Choi et al. found that $\mathrm{HZ}$ did not raise the incidence of dementia (5).

Because of the possible connection between $\mathrm{HZ}$ and dementia, in particular AD, there is hope that an $\mathrm{HZ}$ vaccine might reduce the risk of dementia. In support of this, a lower risk for dementia following adult tetanus, diphtheria, and pertussis vaccination has been documented (6). Other vaccinations [Bacille Calmette-Guérin (BCG), influenza, COVID] may also be associated with reduced AD risk (7-10).

In the current study, we used data from The Behavioral Risk Factor Surveillance System (BRFSS) to evaluate the relationship between $\mathrm{HZ}$ vaccination and cognitive impairment.

\section{Patients and Methods}

The Behavioral Risk Factor Surveillance System (BRFSS) is the most comprehensive US system of health-related telephone surveys, collecting data on U.S. citizens' health-related risk behaviors, chronic health issues, and use of preventive services across the country (11). Recognizing the importance of cognitive decline as a public health concern, the Centers for Disease Control (CDC) through the Alzheimer's Disease and Healthy Aging Program created and deployed a BRFSS module to track subjective cognitive decline and its associated burden in the population, in partnership with national experts. Among the most predictive BRFSS module cognitive questions is one regarding interference with social activities. Social withdrawal is a common early symptom of neuropsychiatric disorders, a major driver of prognosis, and a significant cost to society. As neurological problems worsen, social withdrawal is frequently observed (12).

BRFSS participants are asked how often social activities are hampered by disorientation or memory loss (variable code name CDSOCIAL). We used this information in the current analysis to identify persons whose disorientation or memory loss makes it difficult for them to participate in social activities. 
The interviewer specifically asked the following: During the past 12 months, how often has confusion or memory loss interfered with your ability to work, volunteer, or engage in social activities outside the home? Would you say: 1 -Always; 2 - Usually; 3 - Sometimes; 4 - Rarely; 5 - Never.

The 2017 data, used in the current study, had information on HZ vaccination. Module M07.01 (variable code name SHINGLE2) asks specifically about $\mathrm{HZ}$ vaccination. The interviewer first informs the patient of the following: Shingles is an illness that results in a rash or blisters of the skin and is usually painful. There are two vaccines now available for shingles: Zostavax, which requires 1 shot and Shingrix which requires 2 shots.

The interviewer then asks: Have you ever had the shingles or zoster vaccine?

Responses and their numerical designations were the following: 1. Yes, 2. No, 7. Don't know/Not sure, 9. Refused. In the current study we included only answers 1 and 2 .

The shingles vaccine would be mainly Zostavax (Merck), which was licensed by the FDA on May 26, 2006. Zostavax contains a weakened varicella-zoster virus. Zostavax reduced the risk of shingles by $51 \%$ and the risk of post-herpetic neuralgia by $67 \%$ in a study of more than 38,000 adults aged 60 years or older. Protection from Zostavax wanes after 5 years (13). FDA licensed Shingrix (GSK), a recombinant shingles vaccine on October 20, 2017; therefore, most Shingrix-vaccinated subjects are not included in the 2017 BRFSS data presented here.

Statistical methods. Univariate analysis of BRFSS data was performed by crosstabulation and a contingency table. Because one cell in the table had a zero value, the two tailed Fisher exact test was used to calculate statistical significance. Multivariate analysis was performed with linear regression. SPSS v 25 (IBM, NY, USA) was used for all calculations.

\section{Results}

We studied 275 subjects in the 2017 BRFSS data. Of those, $33 \%$ were male and $67 \%$ were female. The mean age of the 99 subjects who received the $\mathrm{HZ}$ vaccine was $70 \pm 7$ years, whereas the mean age of the 176 subjects who did not receive the vaccine was $65 \pm 10$ years. The age difference is statistically significant $(p<0.001)$.

Table I shows the HZ vaccination status of 275 subjects versus the social activities hampered by disorientation or memory loss. $61.6 \%$ of vaccinated subjects $(n=61)$ never had social activities hampered by disorientation or memory loss, whereas $46.6 \%$ of unvaccinated subjects $(n=82)$ never had social activities hampered by disorientation or memory loss. The difference is statistically significant ( $p=0.025$, two-sided Fisher exact test).

Table II shows the results of multivariate linear regression where social activities hampered by disorientation or memory loss was considered as a dependent variable, whereas vaccination (1 yes or 2 no), sex, and, education level as independent variables. The effect of the vaccinationreducing risk of social activities hampered by disorientation or memory loss was significant $(p=0.03)$.
Table I. Herpes zoster vaccination status in 275 subjects versus social activities hampered by disorientation or memory loss. $61.6 \%$ of vaccinated subjects $(n=61)$ never had social activities hampered by disorientation or memory loss, whereas $46.6 \%$ of unvaccinated subjects $(n=82)$ never had social activities hampered by disorientation or memory loss. The result is significant ( $p=0.025$, two-sided Fisher exact test).

\begin{tabular}{lcccc}
\hline Disoriented & & Vaccinated & Unvaccinated & Total \\
\hline \multirow{2}{*}{ Always } & Count & 8 & 14 & 22 \\
& & $8.10 \%$ & $8.00 \%$ & $8.00 \%$ \\
Usually & Count & 0 & 9 & 9 \\
& & $0.00 \%$ & $5.10 \%$ & $3.30 \%$ \\
Sometimes & Count & 13 & 39 & 52 \\
& & $13.10 \%$ & $22.20 \%$ & $18.90 \%$ \\
Rarely & Count & 17 & 32 & 49 \\
& & $17.20 \%$ & $18.20 \%$ & $17.80 \%$ \\
Never & Count & 61 & 82 & 143 \\
& & $61.60 \%$ & $46.60 \%$ & $52.00 \%$ \\
Total & Count & 99 & 176 & 275 \\
& & $100.00 \%$ & $100.00 \%$ & $100.00 \%$ \\
& & & &
\end{tabular}

Table II. Multivariate linear regression considering social activities hampered by disorientation or memory loss as a dependent variable and vaccination (1 yes or 2 no), sex (1 male, 2 female), and education level as independent variables. B: unstandardized regression coefficient. The effect of vaccination-reducing risk of social activities hampered by disorientation or memory - loss was significant $(p=0.03)$.

\begin{tabular}{lcl}
\hline & B & $p$-Value \\
\hline Vaccination & -0.345 & 0.03 \\
Gender & 0.11 & 0.496 \\
Education & 0.021 & 0.76 \\
\hline
\end{tabular}

\section{Discussion}

Even though vaccinated subjects were on average 5 years older than unvaccinated subjects, more vaccinated subjects $(61.6 \%)$ than unvaccinated subjects $(46.6 \%)$ never had social activities hampered by disorientation or memory loss. One would expect the opposite, since dementia incidence increases with age. Therefore, $\mathrm{HZ}$ vaccination appears to protect against dementia. A weakness in our study is that people whose social activities are unhampered would be more likely to seek vaccination.

About half of all dementia cases are caused by AD (14), but the link between viruses, particularly herpes, and $\mathrm{AD}$ is controversial. There is some evidence that taking anti-herpes drugs for a short period of time reduces the risk of dementia. Infection without antiviral treatment increases the risk somewhat. However, the results do not appear to be consistent across European countries (15). The antibacterial $\beta$-amyloid 


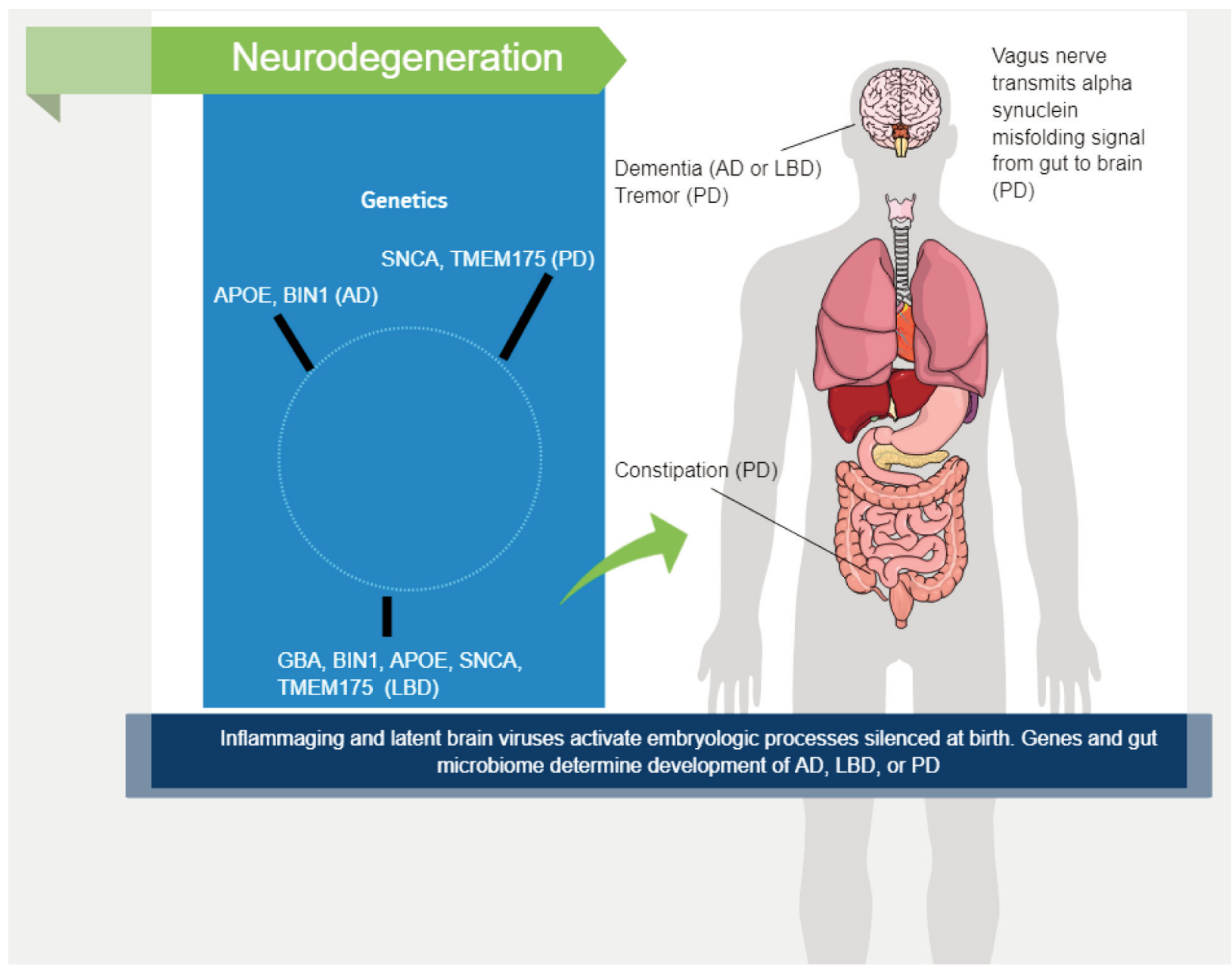

Figure 1. Factors involved in neurodegeneration. GBA, BIN1, APOE, SNCA, and TMEM175 are five genes that have a role in determining whether a person will develop Lewy body dementia ( $L B D)$; some of these genes are also linked to Alzheimer's disease ( $A D)$ and Parkinson's disease (PD). Thus, the pathophysiology and course of $A D, L B D$, and $P D$ would be different, depending on an individual's genome. Although $A D$ and $P D$ are molecularly and clinically distinct disorders, their causes appear to underlie LBD. All three conditions lie on a continuum in vulnerable persons.

found in the brains of $\mathrm{AD}$ patients could protect against herpes simplex type 1 (16), and our finding that $\mathrm{HZ}$ vaccination reduces the risk of dementia is consistent with the link between viruses and $\mathrm{AD}$, which might be mediated by inflammaging.

Inflammation is part of aging. Chronic, sterile, low-grade inflammation, known as inflammaging, develops as people age and is associated with age-related disorders such as AD (17), cerebrovascular disease (18), and diminishing adaptive immunity (19).

AD, Lewy body dementia (LBD), and Parkinson's disease (PD) are all part of a continuum that could explain a variety of age-related neurodegenerative symptoms. Inflammaging is an important part of this process, since it is the long-term effect of persistent physiological stimulation of the innate immune system.
Because it may elaborate inflammatory chemicals and communicate with various organs and systems, the gut microbiome plays a crucial role in inflammaging. The gut microbiota has been linked to Parkinson's disease, and bacteria-produced proteins that mimic misfolded proteins involved in neurodegenerative disease may induce their misfolding (20).

GBA, BIN1, APOE, SNCA, and TMEM175 are five genes that have a role in determining whether a person will develop LBD, and some of these genes are also linked to AD and PD (21). Thus, the pathophysiology and course of AD, LBD, and PD would be different, depending on an individual's genome. Although AD and PD are molecularly and clinically distinct disorders, their causes appear to underlie LBD. All three conditions lie on a continuum in vulnerable persons (Figure 1). 


\section{Conclusion}

Our finding that $\mathrm{HZ}$ vaccination reduces the risk of dementia corroborates the results of other studies linking herpes viruses with $\mathrm{AD}$. Viruses and inflammation are associated with cytokines and growth factors in AD. Furthermore, in the preimplantation embryo, cytokines affect gene expression, metabolism, and cell stress. Around the time of birth, the genes that cause these changes are silenced. However, they could ruin the same neuronal structures they formed in utero if reactivated in the brain by inflammation and viruses decades later. Therefore, herpes virus reactivation of embryologic processes and pathways silenced at birth could be one of the pathologic processes in Alzheimer's disease.

\section{Conflicts of Interest}

The Authors have no conflicts of interest to declare in relation to this study.

\section{Authors' Contributions}

Dr. Lehrer and Dr. Rheinstein contributed equally to the conception, writing, and data analysis of this study.

\section{Acknowledgements}

This work was supported in part through the computational resources and staff expertise provided by Scientific Computing at the Icahn School of Medicine at Mount Sinai.

Research reported in this paper was also supported by the Office of Research Infrastructure of the National Institutes of Health under award numbers S10OD018522 and S10OD026880. The content is solely the responsibility of the Authors and does not necessarily represent the official views of the National Institutes of Health.

\section{References}

1 Chen VC, Wu SI, Huang KY, Yang YH, Kuo TY, Liang HY, Huang KL and Gossop M: Herpes zoster and dementia: A nationwide population-based cohort study. J Clin Psychiatry 79(1): 16m11312, 2018. PMID: 29244265. DOI: 10.4088/JCP.16m11312

2 Bae S, Yun SC, Kim MC, Yoon W, Lim JS, Lee SO, Choi SH, Kim YS, Woo JH, Kim SY and Kim SH: Association of herpes zoster with dementia and effect of antiviral therapy on dementia: a population-based cohort study. Eur Arch Psychiatry Clin Neurosci 271(5): 987-997, 2021. PMID: 32613564. DOI: 10.1007/s00406-020-01157-4

3 Tsai MC, Cheng WL, Sheu JJ, Huang CC, Shia BC, Kao LT and Lin HC: Increased risk of dementia following herpes zoster ophthalmicus. PLoS One 12(11): e0188490, 2017. PMID: 29166672. DOI: 10.1371/journal.pone. 0188490

4 Itzhaki RF and Lathe R: Herpes viruses and senile dementia: First population evidence for a causal link. J Alzheimers Dis 64(2): 363-366, 2018. PMID: 29889070. DOI: 10.3233/JAD180266
5 Choi HG, Park BJ, Lim JS, Sim SY, Jung YJ and Lee SW: Herpes zoster does not increase the risk of neurodegenerative dementia: A case-control study. Am J Alzheimers Dis Other Demen 36: 15333175211006504, 2021. PMID: 33882722. DOI: $10.1177 / 15333175211006504$

6 Scherrer JF, Salas J, Wiemken TL, Jacobs C, Morley JE and Hoft DF: Lower risk for dementia following adult tetanus, diphtheria, and pertussis (Tdap) vaccination. J Gerontol A Biol Sci Med Sci 76(8): 1436-1443, 2021. PMID: 33856020. DOI: 10.1093/gerona/glab115

7 Verreault R, Laurin D, Lindsay J and De Serres G: Past exposure to vaccines and subsequent risk of Alzheimer's disease. CMAJ 165(11): 1495-1498, 2001. PMID: 11762573.

8 Klinger D, Hill BL, Barda N, Halperin E, Gofrit ON, Greenblatt CL, Rappoport N, Linial M and Bercovier H: Bladder cancer immunotherapy by BCG is associated with a significantly reduced risk of Alzheimer's disease and Parkinson's disease. Vaccines (Basel) 9(5): 491, 2021. PMID: 34064775. DOI: 10.3390/vaccines 9050491

9 Kim JI, Zhu D, Barry E, Kovac E, Aboumohamed A, Agalliu I and Sankin A: Intravesical bacillus Calmette-Guérin treatment is inversely associated with the risk of developing Alzheimer disease or other dementia among patients with non-muscleinvasive bladder cancer. Clin Genitourin Cancer, 2021. PMID: 34116955. DOI: 10.1016/j.clgc.2021.05.001

10 Amran A, Lin Y, Kim Y, Bernstam E, Jiang X and Schulz P: Influenza vaccination is associated with a reduced incidence of Alzheimer's disease. Alzheimer's \& Dementia 16(S10), 2020. DOI: 10.1002/alz.041693

11 Pierannunzi C, Hu SS and Balluz L: A systematic review of publications assessing reliability and validity of the Behavioral Risk Factor Surveillance System (BRFSS), 2004-2011. BMC Med Res Methodol 13: 49, 2013. PMID: 23522349. DOI: 10.1186/1471-2288-13-49

12 Gilmour G, Porcelli S, Bertaina-Anglade V, Arce E, Dukart J, Hayen A, Lobo A, Lopez-Anton R, Merlo Pich E, Pemberton DJ, Havenith MN, Glennon JC, Harel BT, Dawson G, Marston H, Kozak R and Serretti A: Relating constructs of attention and working memory to social withdrawal in Alzheimer's disease and schizophrenia: issues regarding paradigm selection. Neurosci Biobehav Rev 97: 47-69, 2019. PMID: 30399355. DOI: 10.1016/j.neubiorev.2018.09.025

13 Baxter R, Bartlett J, Fireman B, Marks M, Hansen J, Lewis E, Aukes L, Chen Y, Klein N and Saddier P: Effectiveness of live zoster vaccine in preventing postherpetic neuralgia (PHN). Open Forum Infectious Diseases 3(suppl_1): 128, 2019. DOI: 10.1093/ofid/ofw194.41

14 Skoog I, Nilsson L, Palmertz B, Andreasson LA and Svanborg A: A population-based study of dementia in 85-year-olds. N Engl J Med 328(3): 153-158, 1993. PMID: 8417380. DOI: 10.1056/NEJM199301213280301

15 Schnier C, Janbek J, Williams L, Wilkinson T, Laursen TM, Waldemar G, Richter H, Kostev K, Lathe R and G Haas J: Antiherpetic medication and incident dementia: Observational cohort studies in four countries. Eur J Neurol 28(6): 1840-1848, 2021. PMID: 33657269. DOI: 10.1111/ene.14795

16 Lehrer S and Rheinstein PH: Alignment of Alzheimer's disease amyloid- $\beta$ peptide and herpes simplex virus-1 pUL15 C-terminal nuclease domain. J Alzheimers Dis Rep 4(1): 373-377, 2020. PMID: 33163898. DOI: 10.3233/ADR-200231 
17 Franceschi C, Garagnani P, Parini P, Giuliani C and Santoro A: Inflammaging: a new immune-metabolic viewpoint for agerelated diseases. Nat Rev Endocrinol 14(10): 576-590, 2018. PMID: 30046148. DOI: 10.1038/s41574-018-0059-4

$18 \mathrm{Li} \mathrm{T}$, Huang Y, Cai W, Chen X, Men X, Lu T, Wu A and Lu Z: Age-related cerebral small vessel disease and inflammaging. Cell Death Dis 11(10): 932, 2020. PMID: 33127878. DOI: 10.1038/s41419-020-03137-x

19 Kasler $\mathrm{H}$ and Verdin E: How inflammaging diminishes adaptive immunity. Nature Aging 1(1): 24-25, 2021. DOI: 10.1038/ s43587-020-00021-3

20 Willyard C: How gut microbes could drive brain disorders. Nature 590(7844): 22-25, 2021. PMID: 33536656. DOI 10.1038/d41586-021-00260-3

21 Chia R, Sabir MS, Bandres-Ciga S, Saez-Atienzar S, Reynolds RH, Gustavsson E, Walton RL, Ahmed S, Viollet C, Ding J, Makarious MB, Diez-Fairen M, Portley MK, Shah Z, Abramzon Y, Hernandez DG, Blauwendraat C, Stone DJ, Eicher J, Parkkinen L, Ansorge O, Clark L, Honig LS, Marder K, Lemstra A, St George-Hyslop P, Londos E, Morgan K, Lashley T, Warner TT, Jaunmuktane Z, Galasko D, Santana I, Tienari PJ, Myllykangas L, Oinas M, Cairns NJ, Morris JC, Halliday GM, Van Deerlin VM, Trojanowski JQ, Grassano M, Calvo A, Mora G, Canosa A, Floris G, Bohannan RC, Brett F, Gan-Or Z, Geiger JT, Moore A, May P, Krüger R, Goldstein DS, Lopez G, Tayebi N, Sidransky E, American Genome Center., Norcliffe-Kaufmann L, Palma JA, Kaufmann H, Shakkottai VG, Perkins M, Newell KL, Gasser T, Schulte C, Landi F, Salvi E, Cusi D, Masliah E,
Kim RC, Caraway CA, Monuki ES, Brunetti M, Dawson TM, Rosenthal LS, Albert MS, Pletnikova O, Troncoso JC, Flanagan ME, Mao Q, Bigio EH, Rodríguez-Rodríguez E, Infante J, Lage C, González-Aramburu I, Sanchez-Juan P, Ghetti B, Keith J, Black SE, Masellis M, Rogaeva E, Duyckaerts C, Brice A, Lesage S, Xiromerisiou G, Barrett MJ, Tilley BS, Gentleman S, Logroscino G, Serrano GE, Beach TG, McKeith IG, Thomas AJ, Attems J, Morris CM, Palmer L, Love S, Troakes C, Al-Sarraj S, Hodges AK, Aarsland D, Klein G, Kaiser SM, Woltjer R, Pastor P, Bekris LM, Leverenz JB, Besser LM, Kuzma A, Renton AE, Goate A, Bennett DA, Scherzer CR, Morris HR, Ferrari R, Albani D, Pickering-Brown S, Faber K, Kukull WA, Morenas-Rodriguez E, Lleó A, Fortea J, Alcolea D, Clarimon J, Nalls MA, Ferrucci L, Resnick SM, Tanaka T, Foroud TM, Graff-Radford NR, Wszolek ZK, Ferman T, Boeve BF, Hardy JA, Topol EJ, Torkamani A, Singleton AB, Ryten M, Dickson DW, Chiò A, Ross OA, Gibbs JR, Dalgard CL, Traynor BJ and Scholz SW: Genome sequencing analysis identifies new loci associated with Lewy body dementia and provides insights into its genetic architecture. Nat Genet 53(3): 294-303, 2021. PMID: 33589841. DOI: 10.1038/s41588-021-00785-3

Received July 12, 2021

Revised September 6, 2021 Accepted September 10, 2021 